\title{
EVALUATION OF MASS HOUSING SETTLEMENTS IN TERMS OF WIND AND NOISE CONTROL: ISTANBUL AND DIYARBAKIR AS A CASE
}

\author{
Gülay ZORER GEDİKa, Neşe YÜĞRÜK AKDAĞ ${ }^{\text {b }}$, Fatih KİRAZ ${ }^{c}$, Bekir ŞENER ${ }^{\mathrm{d}}$, Raşide ÇAÇAN ${ }^{\mathrm{e}}$ \\ ${ }^{a, b}$ Faculty of Architecture, Yildiz Technical University, Istanbul, 34349, Turkey \\ 'Faculty of Fine Arts and Design, Nuh Naci Yazgan University, Kayseri, 38040, Turkey \\ ${ }^{d}$ Naval Architecture and Maritime Faculty, Yildiz Technical University, Istanbul, 34349, Turkey

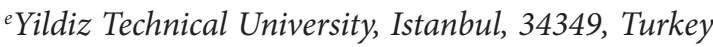

Submitted 25 Jan. 2016; accepted 17 Jan. 2017

\begin{abstract}
In mass housing apartments, the comfort and quality of living conditions may be adversely affected by wind and noise especially on balconies, terraces, gardens and around swimming pools etc. The quantitative and empirical testing of building models according to physical conditions with regard to wind and noise parameters directly affects the formation of buildings in the design process. In this paper, two cities (Istanbul and Diyabakır), which are selected from two different climatic zones in Turkey are considered as examples to create maximum comfortable usage areas depending on wind and noise effects. For mass housing settlement scenarios, common comfortable areas in terms of wind and noise were determined by using Urbawind and soundPLAN softwares. The relevant data and acceptance criteria related to wind and noise and applied procedure are presented in the work. Performed studies show, if the settlements have dominant wind and noise directions, it is possible to find solutions using the geometric properties of the settlement in terms of wind and noise. In general, better comfort results appear in alternatives with L-C-U shaped design features rather than point-type and linear block layouts.
\end{abstract}

Keywords: mass housing, wind control, noise control, environmental processes modeling, environmental impact assessment.

\section{Introduction}

Wind and noise are both physical environment factors that cause serious problems in urban areas and should be considered important in design and planning processes. They also have many negative effects on human health and comfort. While the numbers of mass- housing developments in different climatic zones increase rapidly, the effect of wind speed in open areas especially due to building design has caused an increase in complaints. Additionally, because of locating mass housing close to roads, noise is also a parameter that increases complaints. Searching for solutions to the problems after the design process due to unacceptable wind and noise levels leads to additional costs and unnecessary expenditure of resources. Often, any changes bring additional costs to owners and cause conflicts.

Although the negative effects of wind and noise occur together in plenty of settlements, no study has been presented that provides guidance for combining these parameters in the design of mass housing. Consequently, studies for the optimization of wind and noise parameters in mass housing areas are needed. A great number of studies are available concerning wind and noise individually. When the relevant studies are analysed it can be seen that in urban areas, air flow distribution differs greatly depending on the dimensions of structures, relative positions of one to another and their distribution in a city (Blocken, Carmeliet 2004; Hong, Lin 2015; Shi et al. 2015). Wind has additive, reducing and directing effects on this distribution. Several researches were made studying the creation of comfortable spaces for pedestrians around buildings depending on wind speed and the placing of wind barriers to reduce uncomfortable situations ( $\mathrm{Bu}$ et al. 2009; Aanen, Van Uffelen 2009; Willemsen, Wisse 2007; Stathopoulos 2009; Koss 2006). Wind is one of the main physical causes of erosion. Researchers concentrate on wind barriers designed to protect agricultural land against erosion in areas with strong and continuous wind (Cornelis, Gabriels 2005;

Corresponding author: Bekir Şener

E-mails: bsener@yildiz.edu.tr; brsener@gmail.com 
Nordstrom, Hotta 2004; Campi et al. 2009). Wind tunnel experiments and computer simulation methods are used in studies related to wind (He, Song 1999; Yoshie et al. 2007; Hu, Wang 2004; Hagen et al. 1981; Kubota et al. 2008). Nowadays, it can be seen that simulations are preferred to wind tunnel experiments, since simulations, are faster and cheaper to modify than physical models. Studies of wind barriers, to reduce the negative effects of wind, have focused on engineering calculations rather than architectural design.

Studies on noise and noise control can be collected under many different headings such as the effects of noise on human health and efficiency, evaluation of noise as a design parameter in city and building planning, studies of noise mapping and action plans, and the design of noise barriers. Researches on the effects of noise show that noise starts to disturb when it exceeds 55 Leq $\mathrm{dB}(\mathrm{A})$, and once greater than $65 \mathrm{Leq} \mathrm{dB}(\mathrm{A})$ such disturbance increases significantly and causes serious problems over time (Future Noise Policy (European Commision 1996)). In noise control, starting to evaluate the problem from the city planning level and locating the noise-sensitive outdoor areas and buildings at the required distance from the source of noise is of vital importance. In most developed countries, noise-compatible land use planning decisions are taken at the urban planning stage (FHWA 2006; Chevallier et al. 2009; Murphy, King 2010; King et al. 2011). In making decisions, the noise emitted from industrial facilities is evaluated and definitions specified for noise-sensitive areas and structures as to how far away they are positioned from noise emitting facilities. According to current regulation in Turkey, "The Regulation of Environmental Noise Assessment and Management", it is recommended that exterior noise should not exceed $55 \mathrm{Leq} \mathrm{dB}(\mathrm{A})$ in settlements including sensitive structures (RENAM 2010). Arrangement of buildings according to noise sources is an important parameter in terms of noise level that can reach both outdoor areas and building structures. In the planning stage, positioning the narrow side of the buildings in the direction of noise sources; placing the high and long parallel structures at specific angles to minimize possible sound reflections from structure surfaces are among important design parameters. There are several studies related to determine the effect of the factors on noise environment such as placement and shape of structures, green fields, width and density of the roads and topography (Makarewicz 1991; Thorsson et al. 2004; Baltrénas et al. 2011; Guedes et al. 2011). Guedes et al., have found that the physical characteristics of the urban shape such as construction density, the existence of open spaces, and the shape and physical position of buildings have a significant influance on environmental noise (Guedes et al. 2011). On the other hand, especially for mass housing settlements, there is limited number of studies that deal with design configurations of outdoor activity areas to protect them from noise (FHWA 2006; Desanghere 2007; Montana 2008; Newman, Thornley 1996). A wide range of studies have been performed on the subject of traffic noise control. These studies are mainly related with the usage and importance of barriers in terms of city acoustics (Crombie, Hothersall 1994; Akdağ 2001; Bootby et al. 2001; Watson 2006), selection of suitable equipment/sections for barriers, the form of barriers (Cianfrini et al. 2007; Oldham, Egan 2011; Ishizuka, Fujiwara 2004; Naderzadeh et al. 2011; Venckus et al. 2012), relation between traffic noise, the barrier and the receiver (Hong Kong Environmental Protection Department 2003; Ekici, Bougdah 2003; Watts, Godfrey 1999), visual design criteria for barriers (Kotzen, English 2004; Bendtsen 1994; Maffei et al. 2013), and usage of plants as a noise barrier (Kotzen 2002).

In the architectural design process, solutions in order to prevent wind and noise induced problems can be considered in three groups:

- Settlement

- Barriers around structures

- The building envelope of structures.

In Yildiz Technical University, a research project supported by TUBITAK (The Scientific and Technological Research Council of Turkey) has been completed with the aim of developing a methodology for determining the most suitable settlement formations in terms of wind and noise control for outdoor spaces (Gedik et al. 2014). This project considers five different climatic zones (cold, hot humid, hot dry, temperate humid and temperate dry). The scope of this project is limited to the consideration of human comfort in terms of wind and noise levels for outdoor activities in mass housing settlements. Other specific effects of wind (including turbulence and noise vibration) and noise within the structure are outside the scope of this study. In this paper produced from the TUBITAK project, design configurations of two cities, which are selected from two different climatic zones (temperate humid-Istanbul and hot dry-Diyarbakir) are considered as examples to create maximum comfortable usage areas depending on wind and noise effects taking account of the building bylaws for mass housing in Turkey. The comparative results of other cities will be presented in a later article.

\section{Methodology, data and acceptances}

The methodology of this study consists of three stages:

1. Creating settlement scenarios for mass housing.

2. Determining the relevant data and acceptance criteria related to wind and noise.

3. Determining comfortable areas in terms of wind and noise individually and defining common comfortable areas. 


\subsection{Creating settlement scenarios for mass housing}

Within this paper, the size of a unit house that will be used is taken as $150 \mathrm{sqm}$. This is the upper size limit of a residential zone determined by Turkey Housing Development Fund (Prime Ministry Housing... 1997). Based on this, the width, length and height of the house is specified as $10 \times 15 \times 3 \mathrm{~m}$, respectively.

The joining styles of unit house are defined as pointtype block and linear block, as shown in Figure 1. For pointtype blocks, the quad-joining style is selected since it is the most common type used mainly for economic reasons. Analyses are made for four different number of floors (3, 5, 7 and 10) to assess the effects on the results obtained.

Figure 2 shows the working area ( 1 hectare/10,000 sqm). The width and length of the land is determined as $80 \times 125 \mathrm{~m}$, respectively. To limit the analysis stages, the position of the road relative to the land is chosen to be on one side and parallel to the long edge. "The Turkish Zoning Regulation of Planned Areas" is used to determine the front, side and back yards of the houses (The Zoning Regulation... 1985). The 25 different mass housing settlement configurations considered are shown in Figure 3.

\subsection{Determining the relevant data and acceptance criteria related to wind and noise}

Wind:

It is necessary to determine criteria to define comfortable areas for different climatic conditions, taking into consideration the effects of the wind on a human body. When reviewing the literature in this context the studies on wind speeds that provide comfortable conditions in open areas can be classified by the studies focused on the mechanical effects of wind on the human body (Willemsen, Wisse 2007; Koss 2006; Pendwarden, Wise 1975; Isyumov, Davenport 1975), on thermal effects (Arens et al. 1986; Koch 2002) or both (Stathopoulos 2009; Stathopoulos et al. 2004; Hoppe 2002; Szucs 2004; Szucs et al. 2007). There is no standard published on the mechanical effects of wind. In the quoted studies, it is mostly the wind effects on pedestrian comfort that are discussed. In studies as from Pendwarden (Pendwarden 1973), usually 5m/sec is accepted as a threshold value for uncomfortable situations in terms of the mechanical effects of wind.

Studies concerning the thermal effect of wind are works that consider wind with other microclimate parameters and formulations developed from laboratory and statistical experiments in different parts of the world (Arens et al. 1986; Koch 2002; Stathopoulos et al. 2004).

Among the studies that are focused on both the mechanical and thermal effects of wind, the studies realized by Szucs et al. concerning audience comfort in stadiums are guidelines with their methodological approach (Szucs 2004; Szucs et al. 2007). Required wind speeds are determined for relative humidity of $40 \%, 60 \%$ and $80 \%$ from

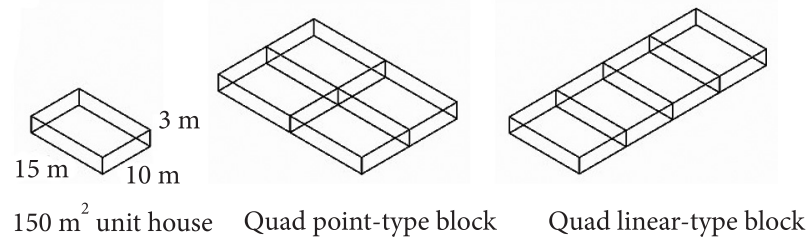

Fig. 1. Joining types of unit house

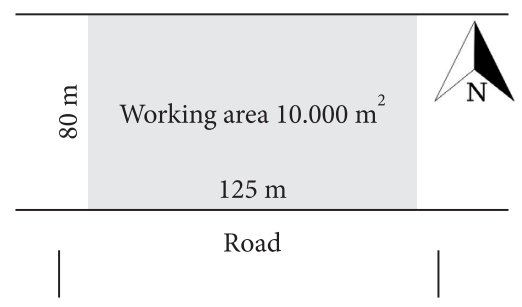

Fig. 2. Dimension and position of land

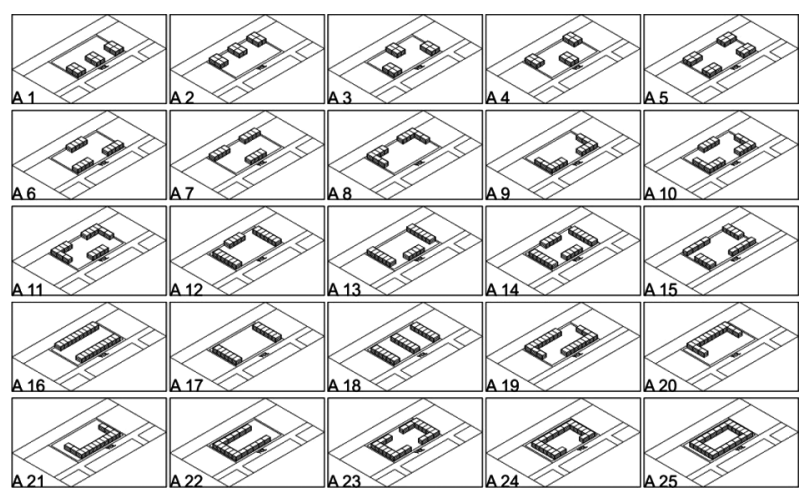

Fig. 3. Mass housing settlement configurations (A1-A5: Point type blocks, A6-A25: Linear type blocks)

rearranged psychometric diagram of Olgyay's bioclimatic comfort chart (Arens et al. 1986). It is considered that Willemsen and Wise used $5 \mathrm{~m} / \mathrm{sec}$ wind speed as a threshold value in their study depending on activity levels (Willemsen, Wisse 2007). A threshold value of wind speed is determined according to climatic regions taking into account maximum acceptable values of wind speed for mechanical effects on the human body and minimum values based on relative humidity. Evaluating the climatic data, $5 \mathrm{~m} / \mathrm{sec}$ wind (light breeze, Beaufort scale) for temperate humid climate region (Istanbul) and $3.6 \mathrm{~m} / \mathrm{sec}$ wind (mechanical threshold) for hot dry climate region (Diyarbakır) are accepted as a threshold values.

In the next stage, to determine the annual acceptable percentage of hours that threshold value is exceeded (exceedance frequency) depending on activity level is important. To specify the annual acceptable exceedance frequency of threshold values indicated by $\mathrm{F}$ in Table 1, the studies in the literature have been examined. The study by Willemsen and Wisse is considered as significant with regards to both defining discomfort potential caused by the mechanical effects of wind on pedestrians and presenting the preparation of new wind comfort regulations in The Netherlands and notes about current studies on wind 
comfort in this regulation (Willemsen, Wisse 2007). Also by considering the annual acceptable wind speed exceedance frequency values (\%) given in the study by Caniot (Caniot et al. 2011; acceptable exceedance frequencies $(F)$ are created depending on activity level for Istanbul and Diyarbakır, as shown in Table 1.

In Table 1 wind speeds are expressed as threshold values $(3.6 \mathrm{~m} / \mathrm{sec}$ and $5 \mathrm{~m} / \mathrm{sec})$ and the acceptable exceedance frequencies indicated as $F(5 \% ; 10 \%)$ are given depending on activity type. In short, $F$ is the annual acceptable percentage of hours that treshold value of wind speed is exceeded.

Table 1. Acceptable exceedance frequencies $(F)$ of wind comfort threshold values $(\mathrm{m} / \mathrm{sec})$ dependent on activity levels (Caniot et al. 2011)

\begin{tabular}{lcc}
\hline Activity type & Diyarbakir & Istanbul \\
\hline Sitting & $F(V>3.6 \mathrm{~m} / \mathrm{sec})<5 \%$ & $F(V>5 \mathrm{~m} / \mathrm{sec})<5 \%$ \\
\hline Walking & $F(V>3.6 \mathrm{~m} / \mathrm{sec})<10 \%$ & $F(V>5 \mathrm{~m} / \mathrm{sec})<10 \%$ \\
\hline
\end{tabular}

In simulations, the wind data received from the Turkish State Meteorological Service for Istanbul and Diyarbakır was used containing daily and hourly measurements over a 30 year period (Archive of Turkish State Meteorological Service 2013). The seasonal wind speeds and directions for Istanbul and Diyarbakir at 6:00, 9:00, 12:00, 15:00, 18:00, 21:00 and 24:00 hours are shown in Figure 4. UrbaWind software has been used for wind comfort simulations (UrbaWind 2013) Wind measurements are gathered at $10 \mathrm{~m}$ height in Turkey. Therefore, a reference point at $10 \mathrm{~m}$ height was defined and calculations were made according to this reference condition. In calculations, the height from ground was taken as $1.5 \mathrm{~m}$ considering the height range that affects the human body. The roughness ratio of the soil directly affects the wind velocity. Urbawind has four types of Roughness length for the inlet profile: $0.05 \mathrm{~m}$ open country, $0.001 \mathrm{~m}$ water, $0.25 \mathrm{~m}$ small density city and $0.7 \mathrm{~m}$ for high denstiy city or forest. $0.25 \mathrm{~m}$ small density city roughness profile has been selected for calculations. Climatologic data can be used as Tab File, Topowind File and TIM File formats in

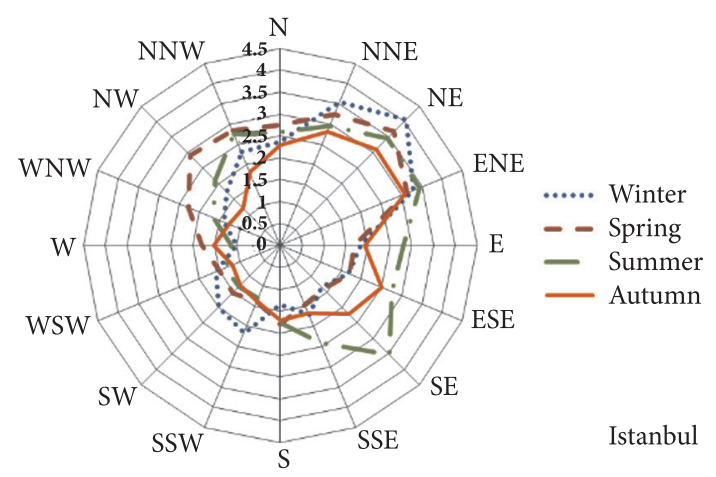

Urbawind. Due to data taken from Turkish State Meteorological Service, Tab File format was used in calculations.

\section{Noise:}

SoundPLAN 7.3 has been used for simulations (Soundplan Manual 2012). In simulations, NMPBRoutes-96 method is used for noise propagation as suggested in EU Noise Directive (EU 2002) and RENAM (RENAM 2010).

In various national and international standards and regulations regarding noise, the noise levels that should not be exceeded are specified based on the region where the structure is located. According to current "Environmental Noise Assessment and Regulation" in Turkey, suggested maximum value of exposure from road traffic is 68 Leq $\mathrm{dB}(\mathrm{A})$ according to settlement region type (RENAM 2010). On the other hand, in many studies conducted in Turkey, the noise generated by roadside was determined to vary between $55 \mathrm{Leq} \mathrm{dB}(\mathrm{A})$ ile $85 \mathrm{Leq} \mathrm{dB}(\mathrm{A})$ by means of noise level measurements and prepared noise maps (Kumbay et al. 2006; Akdağ, Candemir 2009; Aknesil, Akdağ 2011; Dal, Akdağ 2011). In this study, in order to reveal the changes of comfort state of buildings located in different noise environment, the examinations were performed for four different situations that the road noise generate 55, 65, 75 and $85 \mathrm{Leq} \mathrm{dB}(\mathrm{A})$ noise at $1 \mathrm{~m}$ away from the road. Simulations and calculations were realized with the road sound power levels corresponding to these values; $70 \mathrm{~dB}(\mathrm{~A}), 79 \mathrm{~dB}(\mathrm{~A}), 113 \mathrm{~dB}(\mathrm{~A})$ and $123 \mathrm{~dB}(\mathrm{~A})$, respectively. For 55 and $65 \mathrm{Leq} \mathrm{dB}(\mathrm{A})$ the road width is specified as $14 \mathrm{~m}$ and for 75 and $85 \mathrm{Leq} \mathrm{dB}(\mathrm{A})$ the road width is set at $21 \mathrm{~m}$. Individual lane width is taken to be $3.5 \mathrm{~m}$, with refuge and pavement widths of $2 \mathrm{~m}$.

In NMPB Routes method based ISO 9613-2 standard, in noise level calculations from source to receiver it is suggested to use G:0 (where G is the sound absorption features of ground) for low sound absorption surfaces like concrete, G:1 for land areas covered with grass, trees or another vegetation and between 0 and 1 for hard and porous mixed grounds. In this study, ground was assummed to be of mixed type and G was taken to be 0.6 (ISO 9613$2: 1996)$. Road was chosen as asphalt surface. In the calculations, grid space was taken as $10 \mathrm{~m}$, and the height from

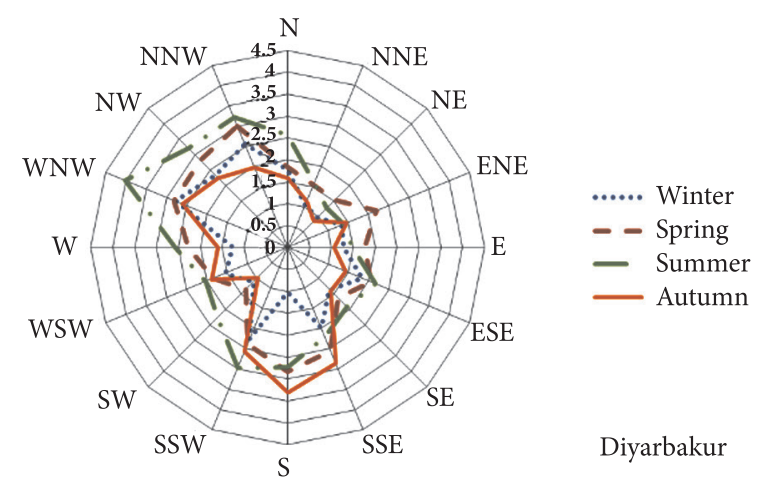

Fig. 4. The seasonal wind speeds $(\mathrm{m} / \mathrm{sec})$ for outdoor use hours for İstanbul and Diyarbakır 
ground as $1.5 \mathrm{~m}$. The effect of wind to noise propagation was taken into account by entering the annual wind frequency distribution to software in 18 directions with angle of 20 degrees and for 2 different time zone, day and night. The wind data was received from the Turkish State $\mathrm{Me}-$ teorological Service and include last 30 years. In Turkey, wind measurements are performed for 16 directions in wind rose with angle of 22,5 degrees (Archive of Turkish State Meteorological Service 2013). Data for angle of 20 degrees, that required to enter to the noise software, was obtained by interpolation of existing data.

The values of the noise value for annoyance are different during the day, evening and night period. The open spaces in mass housung settlements are often used during daylight hours. So, the noise level that should not be exceeded for daylight hours was taken $55 \mathrm{Leq} \mathrm{dB}(\mathrm{A})$, considering the values given in related documents (WHO 1996; RENAM 2010).

\section{Noise Measurements and Validation of the Models}

SoundPLAN, used for noise calculations, is a highly accurate simulation software that both noise sources and environmental data can be defined in detail. It can be found various studies in literature that shows the sensitivity of the software (King, Rice 2009; Guedes et al. 2012; Dal, Akdağ 2011). In order to demonstrate the accuracy of the results obtained in this study, noise map of a part of mass housing located along a road with heavy traffic was prepared, noise level calculations was made at some points and compared with noise level measurements. $1 / 1000$-scaled maps of the working area was provided in electronic form from Istanbul Metropolitan Municipality and transferred to SoundPLAN 7.3 software. These maps are with UTM coordinate system and include terrain elevations ( $x, y, z$ (height)) and building information system (intended use of building, number of floors etc.). There is not a remarkable change in traffic density of the road during the day, the number of vehicles, percentage of heavy vehicles and average speeds were determined based on observation for one hour period, from 10:00 to 11:00 and entered to the software. During the preparation of noise maps, NMPB Routes 96 (Guide de Bruit) standard for highways that was proposed by EU Noise Directive (EU 2002) and RENAM (RENAM 2010) was used. The temperature and relative humidity was measured as $25^{\circ} \mathrm{C}$ and $70 \%$, respectively. The average wind directions and speeds in summer for Istanbul was introduced to the software as wind rose (Archive of Turkish State Meteorological Service 2013). Grid spacing was selected as $10 \times 10 \mathrm{~m}$ in calculations of maps for $1.5 \mathrm{~m}$ height. Noise map of the working area can be seen in Figure 5. Noise level calculations was also performed at points that shown in Figure 6.

All measurements were performed in accordance with the ISO 1996-1 standard (ISO 1996-1:2003) in the

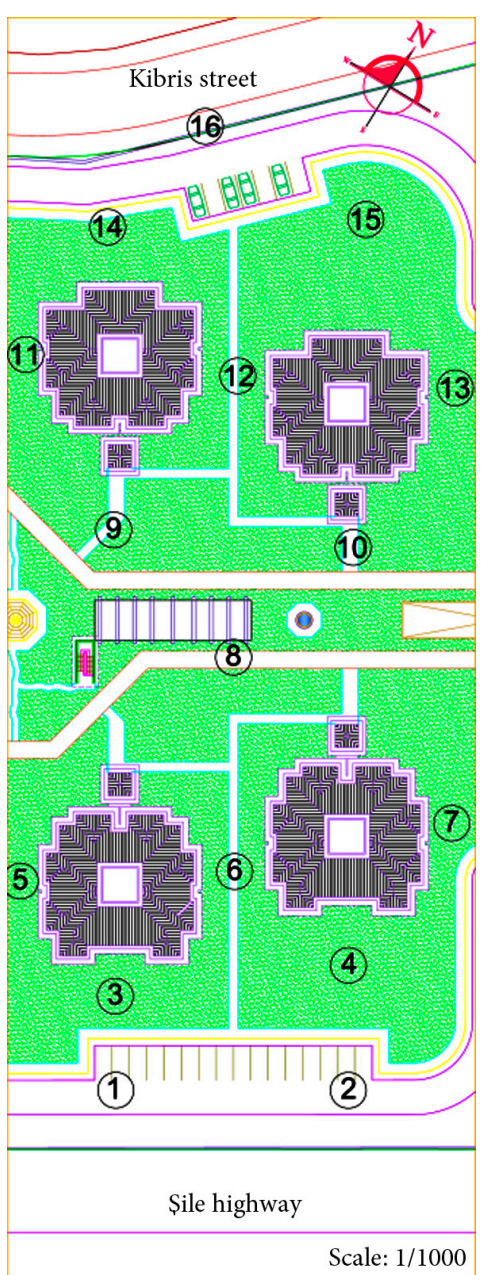

Fig. 5. Noise map of selected area

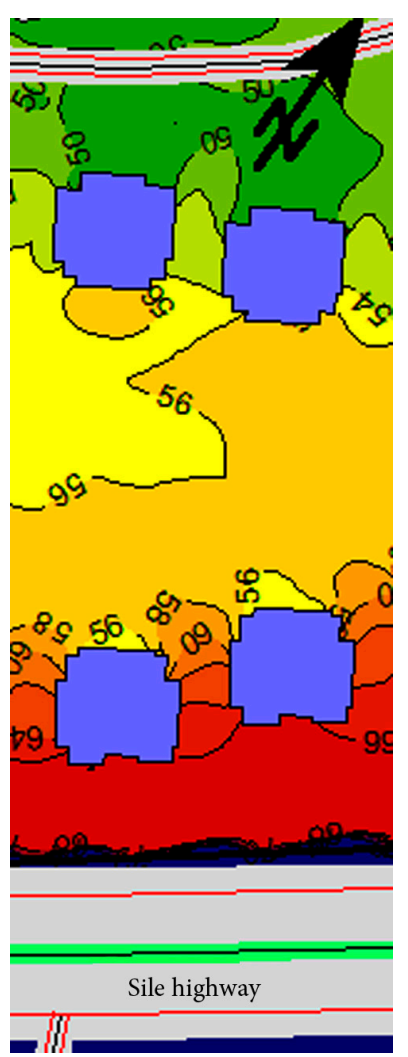

Fig. 6. Noise measurement points 
Table 2. Comparison between measured and calculated noise levels

\begin{tabular}{lccccccccc}
\hline \multicolumn{1}{c}{ Evaluated points } & 1 & 2 & 3 & 4 & 5 & 6 & 7 & 8 \\
\hline Measured Leq dB(A) & 67.5 & 68.0 & 66.5 & 66.0 & 62.0 & 65.0 & 65.5 & 55.0 \\
\hline Calculated Leq dB(A) & 67.0 & 67.2 & 66.0 & 65.5 & 62.6 & 64.8 & 64.0 & 54.2 \\
\hline Difference Leq dB(A) & +0.7 & +0.8 & +0.5 & +0.5 & -0.6 & +0.2 & +1.5 & +0.8 \\
\hline Evaluated points & 9 & 10 & 11 & 12 & 13 & 14 & 15 & 16 \\
\hline Measured Leq dB(A) & 56.0 & 56.7 & 53.0 & 53.0 & 52.2 & 49.0 & 51.5 & 51.5 \\
\hline Calculated Leq dB(A) & 56.8 & 57.5 & 52.0 & 53.4 & 53.5 & 48.5 & 50.8 & 50.5 \\
\hline Difference Leq dB(A) & -0.8 & -0.8 & +1.0 & -0.4 & -1.2 & +0.5 & +0.7 & +1.5 \\
\hline
\end{tabular}

frequency range A, by use of Brüel\&Kjær Type 2250 sound level meter. Measurements were also carried out $1.5 \mathrm{~m}$ above the ground with using a microphone windshield and at least $2 \mathrm{~m}$ away from buildings to prevent any surface reflection. The results of 15 minutes-long measurements and simulations realized for same points were given in Table 2.

According to the Good Practice Guide for Strategic Noise Mapping and the Production of Associated Data on Noise Exposure (WG-AEN 2006), the difference between actual measurement results and the calculated values must not exceed $1 \mathrm{~dB}(\mathrm{~A})$ in a distance of $300 \mathrm{~m}$ from the source, $3 \mathrm{~dB}(\mathrm{~A})$ in a distance of $600 \mathrm{~m}$ from the source and $10 \mathrm{~dB}$ in a distance of 2,000-3,000 $\mathrm{m}$ from the source. As shown in Table 2, the difference of the measurement and simulation results are below $1 \mathrm{~dB}(\mathrm{~A})$ at 14 points and slightly above only at 2 points. Therefore it reveals the reliability of simulation results.

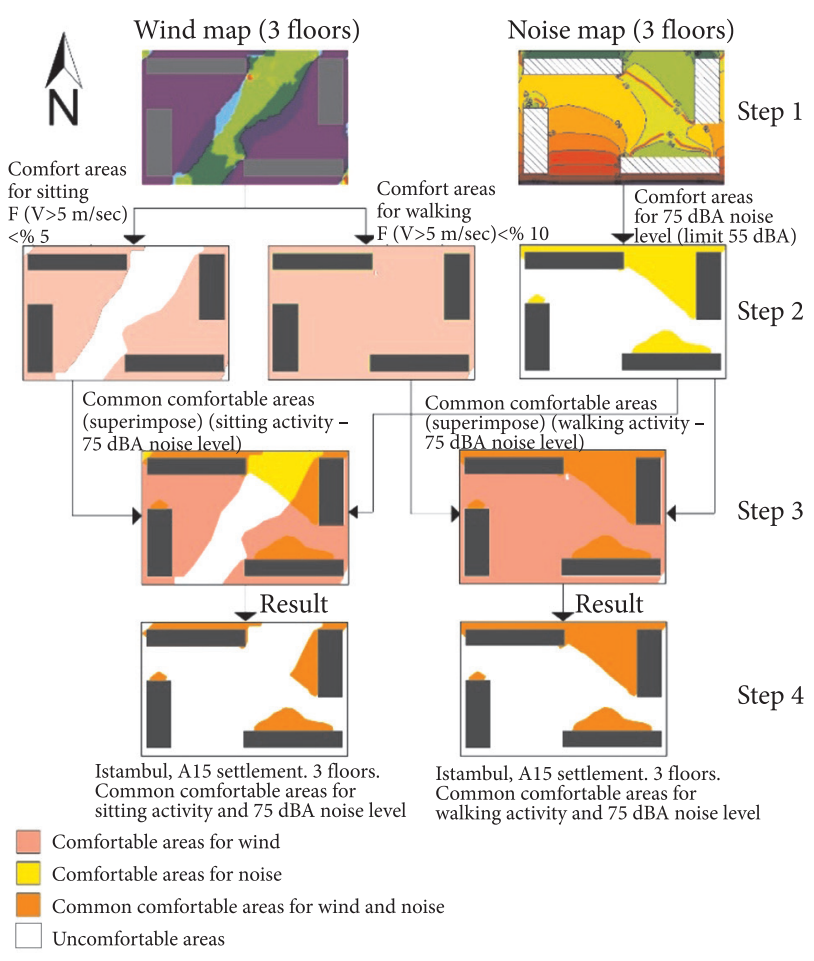

Fig. 7. The schematic procedure to determine the common comfortable areas in terms of wind and noise

\subsection{Determining comfortable areas in terms of wind and noise individually and defining common comfortable areas}

Comfort maps were created for 25 settlement alternatives in Istanbul and Diyarbakir according to different number of floors, noise levels and activity type. The results obtained were evaluated using a diagrammatic approach. Because of differences in calculation methods for the two physical parameters (acceptances, standards, equations, etc.), the comfort maps were initially prepared separately from the different simulations for both parameters and finally superimposed to specify the common comfortable areas. The ratio of common comfortable area to the total open area was calculated and given as a comfort percentage. The schematic procedure to determine the common comfortable areas in terms of wind and noise is given in Figure 7 an example for 3 floors, for an A15 type settlement.

The steps are as follows to determine the comfortable areas (Fig. 7):

- Step 1. to prepare the wind and noise maps separately by using Urbawind and SoundPLAN simulation programs.

- Step 2. to transfer the wind and noise maps to the AutoCAD software and to scan the comfortable areas on maps.

- Step 3. to superimpose the wind and noise comfort maps.

- Step 4. to create a new map by selecting common comfortable areas in terms of wind and noise and determine the ratio of common comfortable area to the total open area.

Following the procedure given above, comparison maps were prepared for 25 settlement alternatives in Istanbul and Diyarbakir. As an example of Step 2, maps showing the comfortable areas in terms of wind and noise are given in Figure 8 and Figure 9 for two alternatives in İstanbul. For the fourth step, sample maps showing the common comfortable areas are given in Figure 10.

As indicated in Section 1.2, in order to take account the effect of wind to noise propagation, the wind data of Istanbul and Diyarbakir was entered to SoundPLAN 


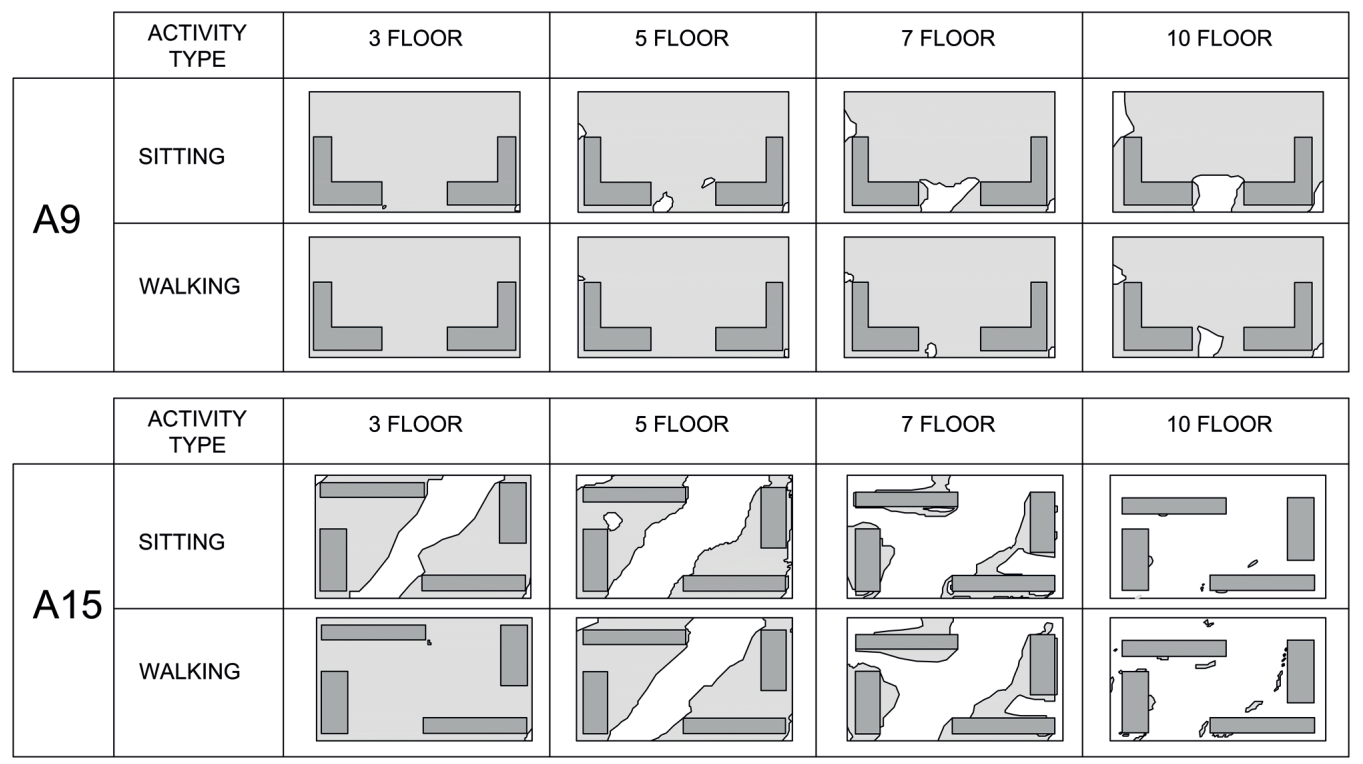

Fig. 8. The variation of comfortable outdoor areas according to mass housing alternatives in terms of wind (Dark grey: house blocks, light grey: comfortable areas, white: uncomfortable areas)

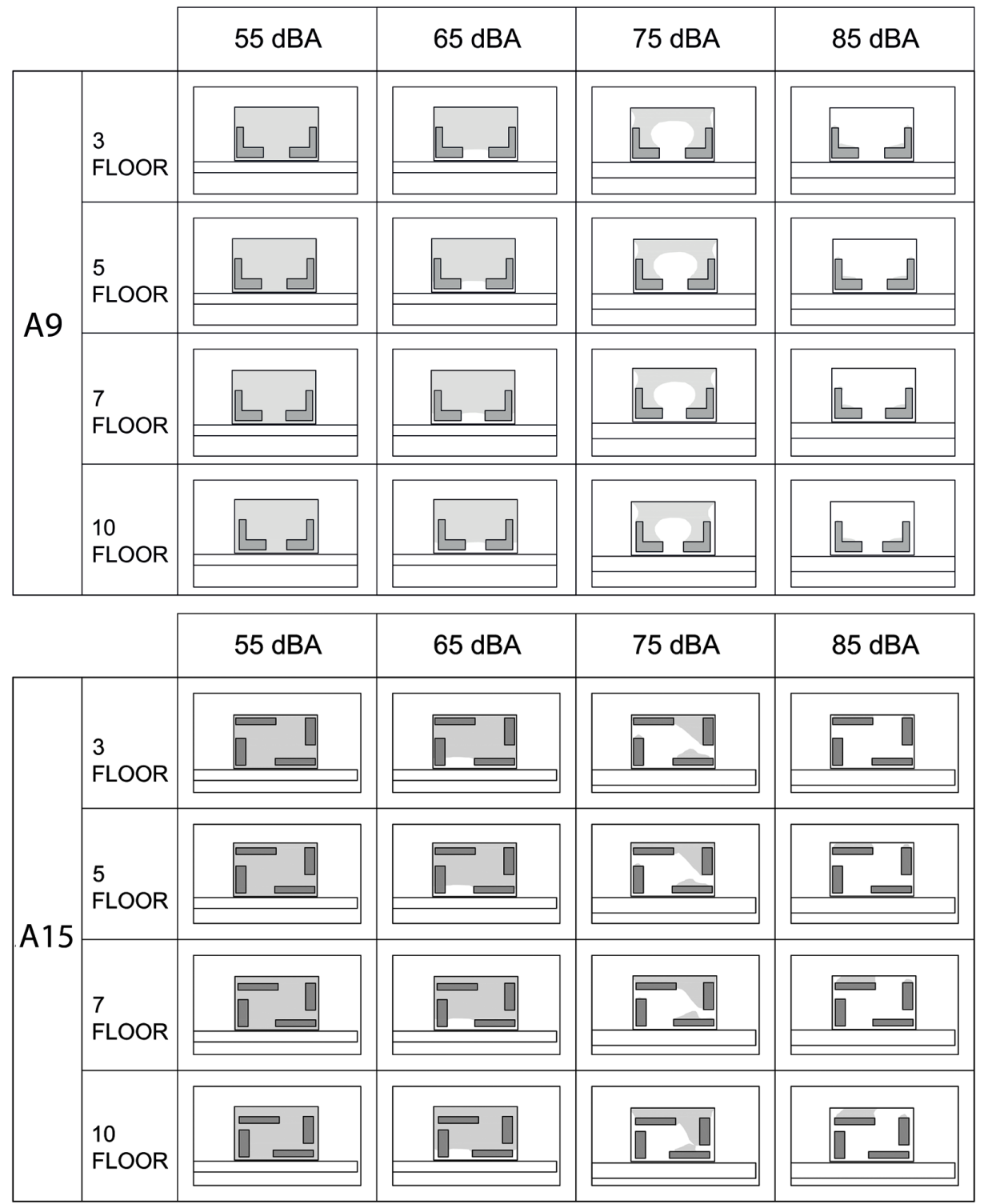

Fig. 9. The variation of comfortable outdoor areas according to mass housing alternatives in terms of noise (Dark grey: house blocks, light grey: comfortable areas, white: uncomfortable areas) 
software. The noise maps generated according to results were compared and the results were found identical. It was presented in previous works that the effect of

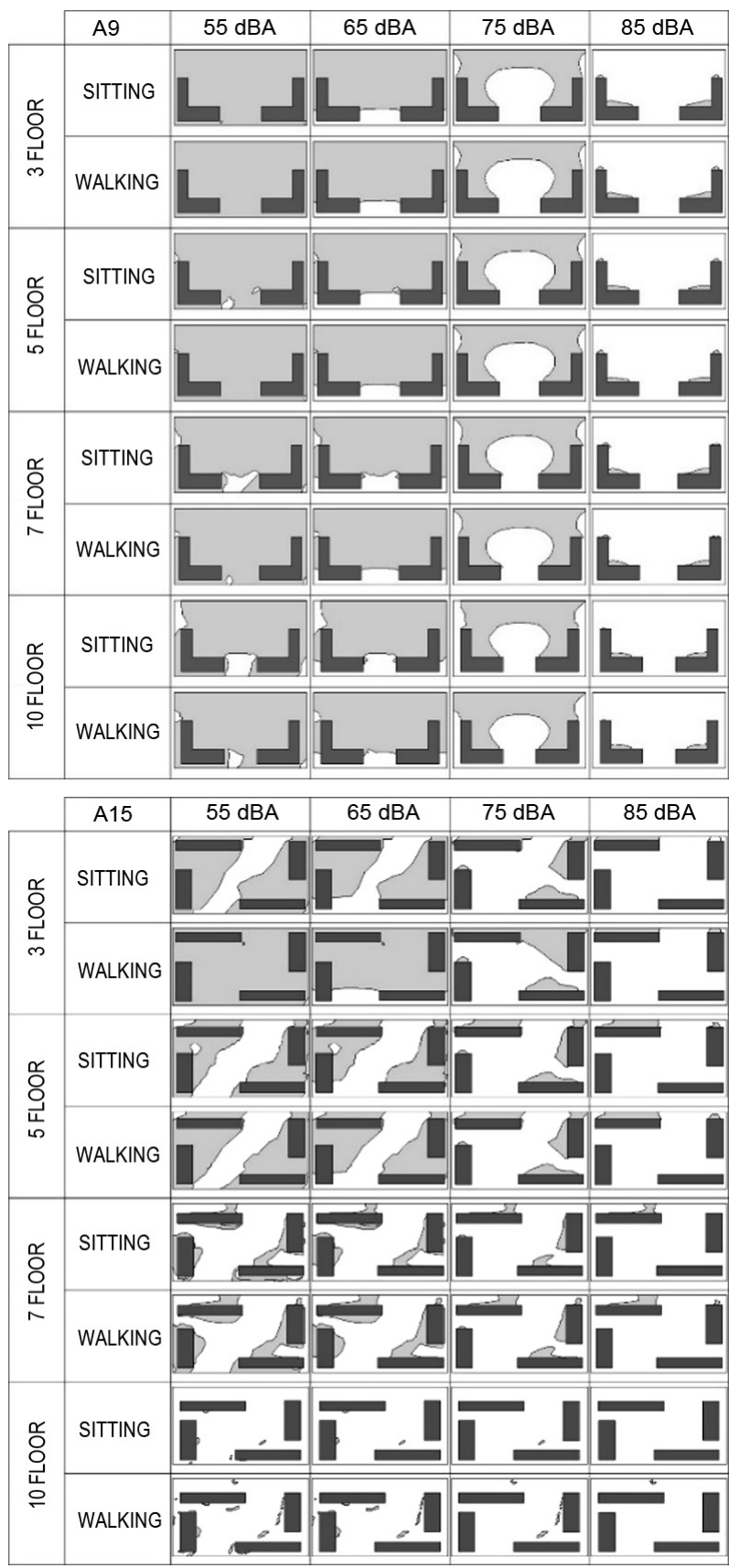

Fig. 10. The variation of comfortable outdoor areas according to mass housing alternatives in terms of wind and noise (Dark grey: house blocks, light grey: comfortable areas, white: uncomfortable areas)

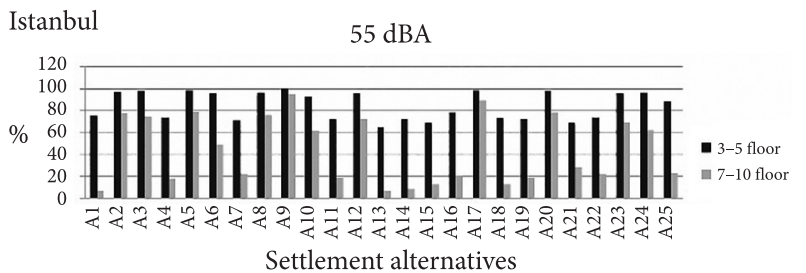

the wind on noise level is important after $50 \mathrm{~m}$ (Harris 1994). In this study, the effect of wind on noise level is very low that cannot be noticed in results because of both the location and size of the parcel and direction and low annually-average speed of wind for Istanbul and Diyarbakir. Therefore, sample maps given in Figure 9 are valid for both Istanbul and Diyarbakir.

\section{Evaluation of open comfortable areas in terms of both wind and noise}

To carry out a general evaluation of common comfortable areas in terms of wind and noise, for each alternative settlement, the average results obtained are grouped according to the number of floors (3-5 floors for low buildings and for 7-10 floors high-rise buildings) and different noise levels. Grouping the percentages of common comfortable areas in terms of both factors in the diagrams for buildings with low and high numbers of floors provides a more robust assessment because it was determined that the comfort percentages in terms of wind show significant variations on high-rise buildings. Results are presented as graphics and evaluated as follows.

55 Leq $\mathrm{dB}(\mathrm{A})$ noise level is the comfort limit value, and $100 \%$ comfortable results were obtained for all settlement alternatives in terms of noise. Therefore, the percentages shown in Figure 11 are values obtained depend on wind.

For Istanbul, A9 and A17 configurations provide maximum comfort percentages both for low and high number of floors because any increase not occurs on outdoor wind speeds due to the structures. (Formation of the settlements do not influence the outdoor wind speed effects with height). A9 configuration with L-shaped structures that close the road side and do not use one-piece block on dominant wind directions (which can increase external wind speed and create channelling effects) gives good results in terms of wind and noise. In addition, configurations where the open area is located in the south and the structures constitute a barrier to the dominant wind direction, northeast and north (A2, A3, A5 from pointtype blocks; A8, A12 and A20 from linear type blocks) are comfortable. The configuration with minimum comfortable area percentage is A13, where the north side is open, consisting of linear blocks vertical to the road and solid blocks that create channel effects. The findings are

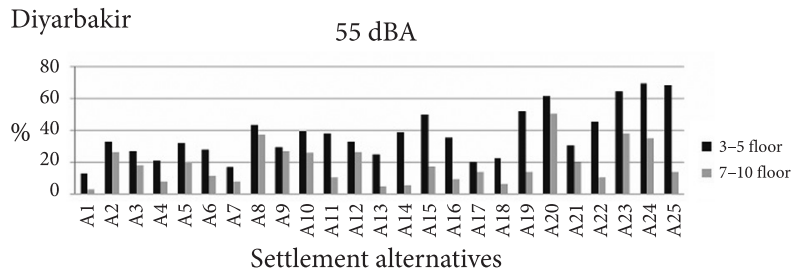

Fig. 11. Averaged comfort percentages of the results of wind and $55 \mathrm{Leq} \mathrm{dB}(\mathrm{A})$ noise level 
different for Diyarbakir as it can be clearly seen that comfort percentages decrease dramatically, especially for point-type blocks. The reason is that the average wind speed values in Diyarbakır are higher compared to Istanbul throughout the year. An increase at comfort percentages can be seen in Figure 11 going from point-type settlements to linear-type. A20 type configuration, where the north side is closed and the open areas positioned on the south side, provide higher comfort percentages for high number of floors. Consequently, A20, A23 and A24 configurations would seem to be good choices. It can also be seen, in configurations where the NE and NW directions are closed with L-shaped structures and in partially open or yard-type houses where the northern directions are completely closed with open areas arranged on the south side, better results are obtained.

In Figure 12, it can be seen that the comfort percentages decrease at $65 \mathrm{Leq} \mathrm{dB}(\mathrm{A})$ noise level and this result is mainly due to wind.

For Istanbul, again A9 and A17 configurations provide maximum comfort percentages both for low and high number of floors. It can be seen that the comfort percentages obtained in terms of noise start to affect common comfortable area percentages. Configurations like A23 with linear type blocks, closed off from the road are better performers than even configuration A17 when considering low numbers of floors. The A5 configuration has good performance no matter how many floors are considered whilst A11 and A13 configurations are the poorest performers. For Diyarbakır, comfort percentages decrease at $65 \mathrm{Leq} \mathrm{dB}(\mathrm{A})$ level but the Figure 12 is very similar to the $55 \mathrm{Leq} \mathrm{dB}(\mathrm{A})$ conditions. Comfort percentages of point-type block configurations are quite low both for low and high number of floors. L-shaped and yard-type linear, C-shaped, inverse closed U-shaped and fully closed
O-shaped configurations (A20, A23, A24, and A25) are good performers for prevailing northerly winds.

In Figure 13, it can be seen that the comfort percentages decrease considerably at $75 \mathrm{Leq} \mathrm{dB}(\mathrm{A})$ noise level and this is mainly due to noise. With increasing noise level, common comfort percentages decrease specifically for configurations consisting of point-type blocks.

For Istanbul, just as for $55 \mathrm{Leq} \mathrm{dB}(\mathrm{A})$ and 65 Leq $\mathrm{dB}(\mathrm{A})$ conditions, the performance of $\mathrm{A} 9$ configuration is remarkably good (51\%) for all numbers of floors (35-7-10) at 75 Leq $d B(A)$. A25 configuration, fully closed yard-type, has a high comfort percentage at $68 \%$ in terms of both wind and noise for low number of floors, but its percentage drops to $17 \%$ because of the unfavorable situation for high number of floors in terms of wind. For yardtype structures with a high number of floors, the air flow that passed over the structure channeled into the yard and created discomfort. The same situation is also valid for A21 and A22 configurations. The performance of the A17 and A20 configurations are poor when compared with configurations that consist of yard-type structures and completely closed road sides like A21 and A25 which provide better performance. For Diyarbakır, especially for point-type blocks and discrete linear-type settlements, the common comfortable area percentages drop to below $10 \%$ in 75 Leq $\mathrm{dB}(\mathrm{A})$ of compared to $20-30 \%$ for wind-weighted 55 and $65 \mathrm{Leq} \mathrm{dB}(\mathrm{A})$ noise levels. The level drops below $20 \%$ for most of the closed linear settlements and close to $30 \%$ is obtained for low number of floors. Only the fully closed yard-type A25 configuration provides 55\% comfort percentage in terms of wind with low number of floors but the percentage drops to only $10 \%$ for high numbers of floors.

In Figure 14, it can be seen that the comfort percentages of suitable usage areas in terms of wind and noise are defined by noise at the $85 \mathrm{Leq} \mathrm{dB}(\mathrm{A})$ level.
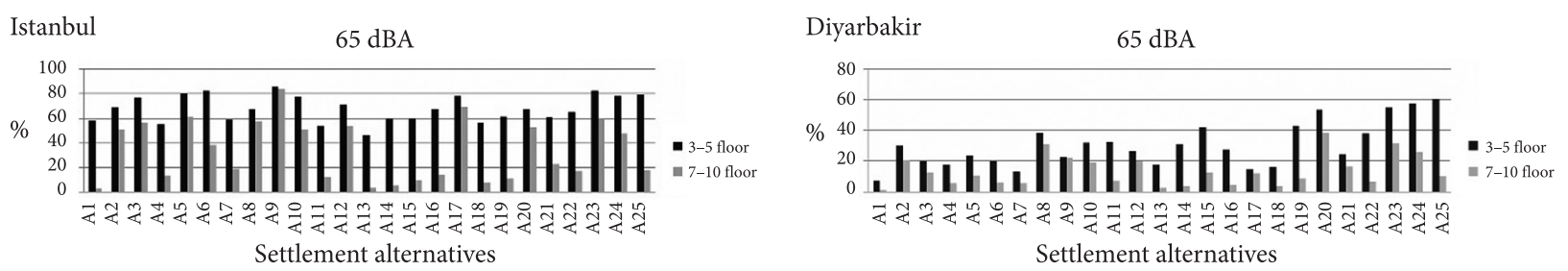

Fig. 12. Averaged comfort percentages of the results of wind and $65 \mathrm{Leq} \mathrm{dB}(\mathrm{A})$ noise level
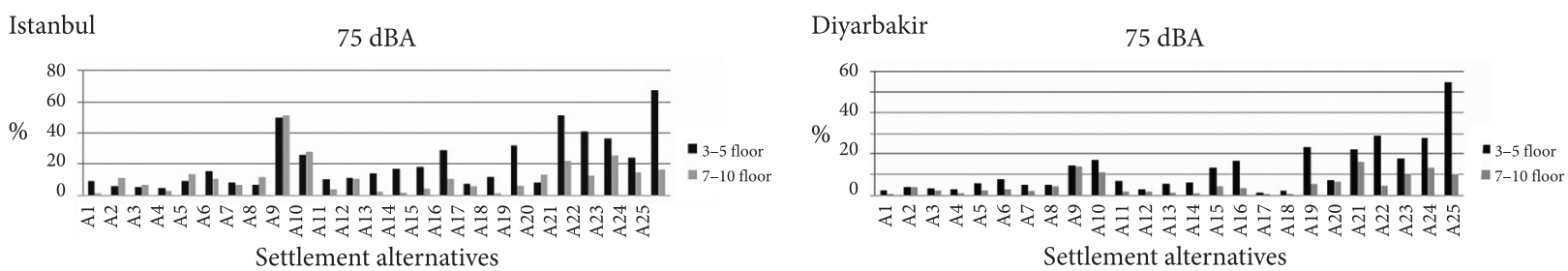

Fig. 13. Averaged comfort percentages of the results of wind and $75 \mathrm{Leq} \mathrm{dB}(\mathrm{A})$ noise level 

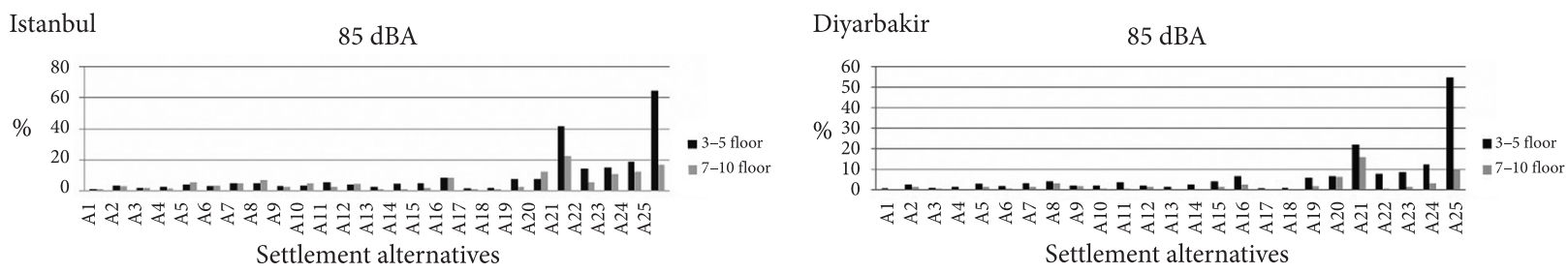

Fig. 14. Averaged comfort percentages of the results of wind and $85 \mathrm{Leq} \mathrm{dB}(\mathrm{A})$ noise level

As illustrated in Figure 14, for Istanbul, there are large decreases in comfort percentages for all settlement alternatives. Except for yard-type A21 and A25 type configurations with low numbers of floors and closed on the road side, comfort percentages are quite low, even dropping to just $1 \%$. The results for comfort percentages are severely affected by the influence of noise. For Diyarbakır, except in linear U-shaped A21 configurations where the road side is completely closed and fully closed yard-type A25 configurations with low numbers of floors, all settlement alternatives have quite low comfort percentages, the majority close to zero. Only A25 configuration with a low number of floors provides around 55\% comfort percentage.

A general review of the results obtained for Istanbul and Diyarbakir for common suitable usage areas in terms of wind and noise conditions is summarized below:

For Istanbul, at $55 \mathrm{Leq} \mathrm{dB}(\mathrm{A})$ and 65 Leq $\mathrm{dB}(\mathrm{A})$ where the wind is dominant in comfort percentages, results are similar. Including point-type blocks, most of settlements are considered to have good performance for both low and high numbers of floors. It can be seen that with increasing noise level, the performance of discrete point-type blocks reduces considerably; linear-type settlements come to the fore and the number of configurations with high comfort percentage decreases. For 3-5 floor settlements, linear configurations come to the fore, whilst for 7-10 floor settlements the comfort percentages are quite low. It can be seen that floor height adversely affects windrelated results and particularly in configurations with 7 floors or more, this effect seems to be very significant.

Since the average wind speed values in Diyarbakır are higher than those recorded at Istanbul throughout the year, comfort percentages and the number of comfortable configurations decrease dramatically. Similar results are obtained in both the 55 and $65 \mathrm{Leq} \mathrm{dB}(\mathrm{A})$ diagrams. For mainly northerly dominated wind directions closed L-shaped and yard-type linear, C-shaped, inverse closed U-shaped and fully closed O-shaped configurations (A20, A23, A24, and A25) perform well.

It is possible to determine configurations with both point-type and linear-type blocks that have high percentages of comfort for İstanbul (an exception being at the $85 \mathrm{Leq} \mathrm{dB}(\mathrm{A})$ noise level in Istanbul). On the other hand, there are significant differences between point-type and linear-type blocks in all the noise level diagrams for Diyarbakır because of the high reduction of comfort level for point-type blocks. Diyarbakır is a difficult city to provide comfort using the geometric properties of a settlement. Point-type and discrete linear settlements perform poorly in Diyarbakir. Only a few settlements with yardtype linear configurations perform acceptably.

At 75 Leq $\mathrm{dB}(\mathrm{A})$ noise level and above, in the options where the blocks are arranged vertical to the road (in a north-south axes), the comfort ratio decreases dramatically. If the blocks are placed parallel to the road as a noise barrier, comfortable areas increase behind the structures. Therefore, improvements occur in comfort values for an alternative arrangement with blocks placed parallel to the road. Better comfort results appear in alternatives with L-C-U shaped design features rather than point-type and linear block layouts. This is related to the sheltered areas created by these layout alternatives from the effects of wind and noise.

\section{Conclusions}

Wind and noise are both physical environmental factors affecting user comfort directly. Because of them open and semi-open spaces cannot be used efficiently. This situation applies particularly in modern-day mass housing developments. Both wind and noise are important components of building physics in the field of determining the sizing for buildings, orienting structures in terms of climatic and noise factors and the design of structural shape and positioning with respect to other nearby structures. In this study, it has been shown that the configuration and positioning of structures in layout plan could be a major source of problems for open areas in terms of wind and noise.

Today, especially high rise identical apartment blocks are seen in the new mass housing settlements in all cities of Turkey like most of other countries. Therefore, this article has revealed the situation experienced in the present and developed solutions and recommendations in terms of wind and noise subjects. The general conclusions of this study are:

1. It has been demonstrated that linear-type settlements give better results compared with point-type block settlements. For block settlements, confi- 
gurations parallel to the road have more comfortable areas than vertical alternatives. Increasing of floor numbers affects both wind and noise comfort adversely. From the perspective of noise control, the main reasons for this situation are the distance of buildings from the road, distance from one another and reflections from buildings surfaces. The configuration and positioning of structures should be determined by consideration of the dominant wind direction and annual variation.

2. Configurations that can create channelling effects along wind directions should be strictly avoided, particularly for high numbers of floors. High apartment blocks are totally unsuited to this kind of settlements as they are more exposed to solar radiation and do not provide sheltered outdoor spaces for the occupants as well.

3. If the settlements have dominant wind and noise directions, it is possible to find solutions using the geometric properties of the settlement in terms of wind and noise.

4. The results presented in this paper show it will be possible to select suitable configurations respecting wind and noise levels based on wind data for a particular city and the position of the structural design according to road position and noise level. However, the scope of this study is limited to providing a guide to human comfort in terms of wind and noise for outdoor activities in mass housing settlements. The effects of wind and noise within the structure could be considered as the subject of another study.

5. It was generally found that the performance of comfortable open spaces is not sufficiently provided for by components such as structural configuration, position and height, so additional considerations are needed. In order to improve the comfort performance of these spaces, recommendations are made to guide the design of wind and noise barriers. It is anticipated that related studies will be presented in a subsequent article.

\section{Funding}

This work was supported by the TUBITAK under Grant $111 \mathrm{M} 560$.

\section{References}

Aanen, L.; Van Uffelen, G. M. 2009. The evaluation of the application of CFD on pedestrian wind comfort in engineering practice, a validation study, in EACWE 5, 19-23 July 2009, Florence, Italy. 9 p.

Akdağ, N. Y. 2001. The use of noise barriers for urban noise control, Journal of Architect and Engineer 30: 80-82 (in Turkish).
Akdağ, N. Y.; Candemir, N. 2009. Importance of noise mapping in urban information systems. Report of state planning organization project. Project No. 26-DPT-03-01-01 (in Turkish).

Aknesil, A. E.; Akdağ, N. Y. 2011. Legal regulations governing noise control in Turkey and examples of environmental noise determination studies in Istanbul, in $6^{\text {th }}$ Annual International Symposium on Environment, 16-19 May 2011, Athens, Greece.

Archive of Turkish State Meteorological Service [online]. 2013 [cited 15 June 2013]. Available from Internet: http://www.mgm.gov.tr

Arens, E. A.; Gonzales, R.; Berqlund, L. 1986. Thermal comfort under an extended range of environmental conditions. Center for the Built Environment, 01 January 1986, UC Berkeley.

Baltrenas, P.; Petraitis, E.; Januševičius, T. 2011. Noise level study and assessment in the southern part of Panevežys, Journal of Environmental Engineering and Landscape Management 18(4): 271-280. https://doi.org/10.3846/jeelm.2010.31

Bendtsen, H. 1994. Visual principles for the design of noise barriers, Science of the Total Environment 146-147: 67-71. https://doi.org/10.1016/0048-9697(94)90221-6

Blocken, B.; Carmeliet, J. 2004. Pedestrian wind environment around buildings: literature review and practical examples, Journal of Thermal Envelope and Building Science 28: 107159. https://doi.org/10.1177/1097196304044396

Bootby, T. E.; Burroughs, C. B.; Bernecker, C. A.; Manbeck, H. B.; Ritter, M. A.; Grgurevich, S.; Cegelka, S.; Lee, P. H. 2001. Design of wood highway sound barriers. USDA Forest Service. Laboratory Research Paper FPL-RP-596, 1-66.

Bu, Z.; Kato, S.; Ishida, Y.; Huang, H. 2009. New criteria for assessing local wind environment at pedestrian level based on exceedance probability analysis, Building and Environment 44: 1501-1508. https://doi.org/10.1016/j.buildenv.2008.08.002

Campi, P.; Palumbo, A. D.; Mastrorilli, M. 2009. Effects of tree windbreak on microclimate and wheat productivity in a Mediterranean environment, European Journal of Agronomy 30: 220-227. https://doi.org/10.1016/j.eja.2008.10.004

Caniot, G.; Li, W.; Dupont, G. 2011. Validations and applications of a CFD tool dedicated to wind assessment in urban areas [online], [cited 10 August 2013]. Available from Internet: http://meteodyn.com/wp-content/uploads/2012/06/Validations-and-applications-of-a-CFD-tool-dedicated-to-windassessment-in-urban-areas.pdf

Chevallier, E.; Can, A.; Nadji, M.; Leclercq, L. 2009. Improving noise assessment at intersections by modeling traffic dynamics, Transportation research part D, Transport and Environment 14/2: 100-110. https://doi.org/10.1016/j.trd.2008.09.014

Cianfrini, C.; Corcione, M.; Fontana, L. 2007. Experimental verificationof the acoustic performance of diffusive roadside noise barriers, Applied Acoustics 68(11-12): 1357-1372. https://doi.org/10.1016/j.apacoust.2006.07.018

Cornelis, W. M.; Gabriels, D. 2005. Optimal windbreak design for wind-erosion control, Journal of Arid Environments 61: 315-332. https://doi.org/10.1016/j.jaridenv.2004.10.005

Crombie, D. H.; Hothersall, D. C. 1994. The acoustic performance of multiple edge noise barriers, in Inter-noise 94, 2931 August 1994, Yokohama, Japan.

Dal, Z.; Akdağ, N. Y. 2011. Noise disturbance caused by outdoor activities-a simulated environment study for Ali Sami Yen stadium, Istanbul, Environmental Monitoring and Assessment 174/1: 347-360.

https://doi.org/10.1007/s10661-010-1462-z 
Desanghere, G. 2007. QCITY: Providing cities a guide for noise action plans, in Inter-noise 2007, 28-31 August, Istanbul, Turkey.

Ekici, I.; Bougdah, H. A. 2003. Review of research on environmental noise barriers, Building Acoustics 10/4: 289-323. https://doi.org/10.1260/135101003772776712

EU. 2002. EU Noise Directive, 2002/49/EC [online], [cited 20 July 2014]. Available from Internet: http://ec.europa.eu/environment/noise/directive_en.htm

European Commision. 1996. Future Noise Policy. European Commission Green Paper. November, Brussels, Belgium.

FHWA. 2006. Noise compatible land use curriculum [online]. US Federal Highway Administration, Department of Transportation [cited 15 July 2014]. Available from Internet: http:// www.fhwa.dot.gov/environment/noise/nnoise _compatible_ planning/ workshops/ncp_curr.pdf

Gedik, G. Z.; Akdağ, N. Y.; Sener, B.; Kiraz, F.; Çaçan, F. 2014. Optimization of mass housing settlements in terms of wind and noise control. Report of TUBITAK 1001 Project, Pr. No. 111M560 (in Turkish).

Guedes, I. C. M.; Bertoli, S. R.; Zannin, P. H. T. 2011. Influence of urban shapes on environmental noise: a case study in Aracaju - Brazil, Science of the Total Environment 412: 66-76. https://doi.org/10.1016/j.scitotenv.2011.10.018

Hagen, L. J.; Skidmore, E. L.; Miller, P. L.; Kipp, J. E. 1981. Simulation of effect of wind barriers on airflow, ASAE 24: 10021008.

Harris, C. M. 1994. Noise control in buildings. McGraw-Hill Inc., USA.

He, J.; Song, C. S. 1999. Evaluation of pedestrian winds in urban area by numerical approach, Journal of Wind Engineering and Industrial Aerodynamics 81: 295-309. https://doi.org/10.1016/S0167-6105(99)00025-2

Hong, B.; Lin, B. 2015. Numerical studies of the outdoor wind environment and thermal comfort at pedestrian level in housing blocks with different building layout patterns and trees arrangement, Renewable Energy 73: 18-27. https://doi.org/10.1016/j.renene.2014.05.060

Hong Kong Environmental Protection Department. 2003. Guidelines on design of noise barriers [online], [cited 10 December 2013]. Available from Internet: http://www.hyd.gov.hk/en/ publications_and_publicity/publications/technical_document/guidelines_on_noise_barriers/index.html

Hoppe, P. 2002. Different aspects of assessing indoor and outdoor thermal comfort, Energy and Buildings 34: 661-665. https://doi.org/10.1016/S0378-7788(02)00017-8

$\mathrm{Hu}, \mathrm{C}$.; Wang, F. 2004. Using a CFD approach for the study of street-level winds in a built-up area, Building and Environment 40: 617-631. https://doi.org/10.1016/j.buildenv.2004.08.016

Ishizuka, T.; Fujiwara, K. 2004. Performance of noise barriers with various edge shapes and acoustical conditions, Applied Acoustics 65: 125-141. https://doi.org/10.1016/j.apacoust.2003.08.006

ISO 1996-1:2003. Acoustics - description, measurement and assessment of environmental noise - Part 1: Basic Quantities and Assessment Procedures.

ISO 9613-2:1996. Acoustics, attenuation of sound during propagation outdoors - Part 2: General method of calculation.

Isyumov, N.; Davenport, A. G. 1975. The ground level wind environment in built up areas, in $4^{\text {th }}$ International Conference on
Wind Effects on Buildings and Structures, 1975, London, UK.

King, E. A.; Murphy, E.; Rice, H. J. 2011. Implementation of the EU environmental noise directive: lessons from the first phase of strategic noise mapping and action planning in Ireland, Journal of Environmental Management 92(3): 756-754. https://doi.org/10.1016/j.jenvman.2010.10.034

King, E. A.; Rice, H. J. 2009. The development of a practical framework for strategic noise mapping, Applied Acoustics 70(8): 1116-1127. https://doi.org/10.1016/j.apacoust.2009.01.005

Koch-Nielsen, H. 2002. Stay cool. A Design Guide for the Built Environment in Hot Climates. Earthscan Publications Ltd.

Koss, H. H. 2006. On differences and similarities of applied wind comfort criteria, Journal of Wind Engineering and Industrial Aerodynamics 94: 781-797. https://doi.org/10.1016/j.jweia.2006.06.005

Kotzen, B. 2002. Plants and environmental noise barriers, in International Conference on Urban Horticulture, 2-6 September 2002, Waedenswil, Switzerland.

Kotzen, B.; English, C. 2004. Environmental noise barriers, a guide to their acoustic and visual design. $2^{\text {nd }}$ ed. USA: Taylor\&Francis.

Kubota, T.; Miura, M.; Tominaga, Y.; Mochida, A. 2008. Wind tunnel test on the relationship between building density and pedestrian-level wind velocity: development of guidelines for realizing acceptable wind environment in residential neighborhoods, Building and Environment 43: 1699-1708. https://doi.org/10.1016/j.buildenv.2007.10.015

Kumbay, A.; Yüksel, Z.; Akdağ, N. Y.; Can, C. 2006. Evaluation of urban noise problems: historical peninsula case study, in Euronoise 2006, 30 May - 1 June, Tempere, Finland.

Maffei, L.; Masullo, M.; Aletta, F.; Aletta, F.; Di Gabriele, M. 2013. The influence of visual characteristics of barriers on railway noise perception, Science of the Total Environment 445-446: 41-47. https://doi.org/10.1016/j.scitotenv.2012.12.025

Makarewicz, R. 1991. Traffic noise in a built-up area, Applied Acoustics 31(3): 37-50. https://doi.org/10.1016/0003-682X(91)90045-G

Montana Department of Transportation. 2008. Growing neighborhoods in growing corridors: land use planning for highway noise. Report no. FHWA/MT-08-002/8117-36, US.

Murphy, E.; King, E. A. 2010. Strategic environmental noise mapping: methodological issues concerning the implementation of the EU noise directive and their policy implications, Environment International 36-3: 290-98.

Naderzadeh, M.; Monazzam, M. R.; Nassiri, P.; Bellah Fard, S. M. 2011. Application of perforated sheets to improve the efficiency of reactive profiled noise barriers, Applied Acoustics 72(6): 393-398. https://doi.org/10.1016/j.apacoust.2011.01.002

Newman, P.; Thornley, A. 1996. Urban planning in Europe. $1^{\text {st }}$ ed. London: Routledge, 60-61. https://doi.org/10.4324/9780203427941

Nordstrom, K. F.; Hotta, S. 2004. Wind erosion from cropland in the USA: a review of problems, solutions and prospects, Geoderma 121: 157-167. https://doi.org/10.1016/j.geoderma.2003.11.012

Oldham, D. J.; Egan, C. A. A. 2011. Parametric investigation of the performance of T-profiled highway noise barriers and the identification of a potential predictive approach, Applied Acoustics 72: 803-813. https://doi.org/10.1016/j.apacoust.2011.04.012 
Pendwarden, A. D. 1973. Acceptable wind speeds in towns, Building Science 8: 259-267. https://doi.org/10.1016/0007-3628(73)90008-X

Pendwarden, A. D.; Wise, A. F. E. 1975. Wind environment around buildings. Building Research Establishment Digest.

RENAM. 2010. The Regulation of Environmental Noise Assessment and Management. The Official Gazette, No. 25862, Turkey.

Shi, X.; Zhu, Y.; Duan, J.; Shao, R.; Wang, J. 2015. Assessment of pedestrian wind environment in urban planning design, Landscape and Urban Planing 140: 17-28. https://doi.org/10.1016/j.landurbplan.2015.03.013

SoundPLAN manual V 7.3. 2012. Backnang: Braustain+Berndt GMBH.

Stathopoulos, T. 2009. Wind and Comfort, in Eacwe 5, 19-23 July 2009, Florence, Italy.

Stathopoulos, T.; Wu, H.; Zacharias, J. 2004. Outdoor human comfort in an urban climate, Building and Environment 39: 297-305. https://doi.org/10.1016/j.buildenv.2003.09.001

Szucs, A. 2004. Stadia in the environment - environment in stadia, in Plea2004 - The 21 $1^{\text {th }}$ Conference on Passive and Low Energy Architecture, 19-22 September, Eindhoven, The Netherlands.

Szucs, A.; Moreau, S.; Allard, F. 2007. Spectators' aerothermal comfort assessment method in stadia, Building and Environment 42: 2227-2240.

https://doi.org/10.1016/j.buildenv.2006.03.009

The zoning regulation of planned areas, The Official Gazette No. 18916, 1985, Turkey.

Prime Ministry housing development administration regulations for the implementation of the public housing loans, The Official Gazette No. 23019, 14 June, 1997, Turkey.

Thorsson, P. J.; Ogren, M.; Kropp, W. 2004. Noise levels on the shielded side in cities using a flat city model, Applied Acoustics 65/4: 313-323. https://doi.org/10.1016/j.apacoust.2003.11.005
UrbaWind [online]. 2013 [cited July 2016]. Available from Internet: http://meteodyn.com/en/logiciels/cfd-wind-pedestriancomfort-safety-urbawind-software/\#.WB8wGvmLTDc

Venckus, Z.; Grubliauskas, R.; Venslovas, A. 2012. Research on the effectiveness of the inclined top type of a noise barrier, Journal of Environmental Engineering and Landscape Management 20(2): 155-162. https://doi.org/10.3846/16486897.2011.634068

Watson, D. 2006. Evaluation of benefits and opportunities for innovative noise barrier designs. Report for Arizona Department of Transportation, Report no. 572, November, USA.

Watts, G. R.; Godfrey, N. S. 1999. Effects on roadside noise levels of sound absorption materials in noise barriers, Applied Acoustics 58: 385-402. https://doi.org/10.1016/S0003-682X(99)00007-9

WG-AEN. 2006. European Commission Working Group. Good practice guide for strategic noise mapping and the production of associated data on noise exposure [online], [cited July 2016]. Available from Internet: http://ec.europa.eu/environment/noise/pdf/wg_aen.pdf

WHO. 1996. Guidelines for community Noise-5 noise management. World Health Organization.

Willemsen, E.; Wisse, J. A. 2007. Design for wind comfort in the Netherlands: procedures, criteria and open research issues, Journal of Wind Engineering and Ind. Aerodynamics 95: 15411550. https://doi.org/10.1016/j.jweia.2007.02.006

Yoshie, R.; Mochida, A.; Tominaga, Y.; Kataoka, H. 2007. Cooperative project for CFD prediction of pedestrian wind environment in the architectural institute of Japan, Journal of Wind Engineering and Industrial Aerodynamics 95: 15511578. https://doi.org/10.1016/j.jweia.2007.02.023

Gülay ZORER GEDİK is a Professor at the Faculty of Architecture of Yildiz Technical University, Turkey. She received her PhD in Building Physics from Yildiz Technical University, Istanbul in 1995. She is especially interested in the whole process of Climatic Building Design and Energy Efficient Building Principles and Wind and Solar Architecture. She has completed eight research projects. Her last (project coordinator) research project's title is "Optimization of mass-housing settlements in terms of wind and noise control". She has worked for the National Building Energy Calculation Methodology Improvement Project (as a coordinator of Net Energy part). She has published many peer-reviewed scientific articles in high impact journals and presented many papers at international and national conferences.

Neșe YÜĞRÜK AKDAĞ. She studied at Yildiz Technical University and obtained a degree in Architecture in 1984, an MSc degree in "Building Physics" in 1987, and received her PhD in "Architectural Acoustics" from Yildiz Technical University in 1995. She is full professor since 2011 in Building Physics Unit of the Faculty of Architecture in Yildiz Technical University. She has range of articles, papers, books and applications on room and building acoustics. She has also several researches on noise mapping. She prepared and organized some national projects and contributed to several national and international projects. She is a member of the Turkish Acoustical Society.

Fatih KİRAZ. He is an Assistant Professor at the Faculty of Fine Arts and Design of Nuh Naci Yazgan University, Turkey. He received his PhD in Building Physics from Yildiz Technical University, Istanbul in 2015. He is especially interested in the whole process of Climatic Building Design and Noise Control and Wind and Solar Architecture. He has participated as a scholar to the research Project "Optimization of mass-housing settlements in terms of wind and noise control".

Bekir ŞENER. He is an Assistant Professor at the Naval Architecture and Maritime Faculty of Yildiz Technical University, Turkey and currently the Vice Head of Department of Naval Architecture and Marine Engineering. He received his PhD in Naval Architecture from Yildiz Technical University, in 2012. His research interest include design of ship and yachts, hydrodynamics, 3D modeling and CFD. He has participated as a researcher to the "Optimization of mass-housing settlements in terms of wind and noise control" project. He also prepared and contributed several national projects.

Raşide ÇAÇAN. She studied at Yildiz Technical University and received Bachelor degree in Architecture in 2008, and MSc degree in "Building Physics" in 2014. She has participated as a scholar to the "Optimization of mass-housing settlements in terms of wind and noise control" project. 